\title{
Clinical Manifestations of Self-disorders in Schizophrenia Spectrum Conditions
}

\author{
Mads Gram Henriksen ${ }^{1,2,3}$ A,E, Josef Parnas ${ }^{1,2,4}{ }_{A, E}$ \\ ${ }^{1}$ Mental Health Center Glostrup, University Hospital of Copenhagen \\ ${ }^{2}$ Center for Subjectivity Research, University of Copenhagen \\ ${ }^{3}$ Department of Media, Cognition and Communication, Philosophy Section, University of Copenhagen \\ ${ }^{4}$ Institute of Clinical Medicine, Faculty of Health and Medical Sciences, University of Copenhagen
}

\begin{abstract}
This article explores the phenomenologically informed, theoretical and empirical research direction on self-disorders in the schizophrenia spectrum conditions. First, we describe the concept of 'self' that is operative in the concept of 'self-disorders' and we discuss how this self may be disordered or fragile in the schizophrenia spectrum. Second, we offer a detailed psychopathological presentation and discussion of 3 patients with schizophrenia. The vignettes provide paradigmatic examples of self-disorders in schizophrenia. Third, we summarize the main findings in the current empirical research on self-disorders. These findings consistently indicate that selfdisorders constitute a crucial, trait phenotype of the schizophrenia spectrum.
\end{abstract}

Keywords: EASE; anomalous self-experience; schizotypal disorder

\section{Introduction}

For a long time, the concept of self has been absent in the diagnostic manuals. Though not mentioned in the current schizophrenia definitions in ICD-10 [1] and DSM-5 [2], 'disturbances of self-experience' (i.e. self-disorders) has recently been included as a defining feature of schizophrenia in the beta-version of the ICD-11. ${ }^{1}$ Whether or not this change will facilitate a shift in our understanding of schizophrenia remains to be seen. Still, including self-disorders in the schizophrenia definition entails, at least potentially, a shift away from defining the disorder as a primarily delusionalhallucinatory clinical phenotype towards a possibly more Bleulerian understanding of schizophrenia. In his seminal textbook [3], Bleuler famously distinguished between fundamental and accessory symptoms of schizophrenia, arguing that the fundamental symptoms are essential to schizophrenia, whereas the accessory symptoms are not. Bleuler listed a group of so-called fundamental symptoms, either complex such as autism and experiential egodisorders or simple such ambivalence, etc. The description of experiential ego-disorders makes it clear that Bleuler identified very basic disturbances of the sense of identity and self-presence. The fundamental symptoms overlap each other and the most central concept is that of autism, which comprises changes in expressivity, subjectivity, and intersubjectivity [4]. According to Bleuler, the fundamental symptoms exhibit a trait-like quality-

\footnotetext{
${ }^{1}$ http://apps.who.int/classifications/icd11/browse/lm/en\#/http\%3a\%2f\%2fid.who.int\%2ficd\%2fentity\%2f1683919430
}

"[they] are present in every case and at every period of the illness" [3, p. 13]. By contrast, accessory symptoms, which, on his account, include delusions, hallucinations, and various catatonic features, are more state-like phenomena, episodic in nature, and may also be found in other psychotic disorders. Though such accessory symptoms occasionally may dominate the clinical picture, they can also be completely absent. With regard to differentialdiagnostic considerations, Bleuler was exceptionally clear-the only decisive diagnostic factor, separating schizophrenia from manic or depressive psychosis, is the presence of fundamental symptoms [3, p. 304].

Today, Bleuler's psychopathological insights have been all but lost. Among his crucial, fundamental symptoms, only severe forms of formal thought disorders made it into the current schizophrenia definitions. Despite cautionary remarks from the editors of the DSM, the diagnostic criteria are often not viewed, as proposed, as mere gatekeepers to diagnoses ("as guidelines for making diagnoses") 2 but as almost exhaustive of the psychopathology of these disorders. In other words, much of the psychopathological wisdom of eminent clinicians from

\footnotetext{
${ }^{2}$ For example, DSM-IV includes the following statement: "The specific diagnostic criteria included in DSM-IV are meant to serve as guidelines to be informed by clinical judgment and are not meant to be used in a cookbook fashion. For example, the exercise of clinical judgment may justify giving a certain diagnosis to an individual even though the clinical presentation falls just short of meeting the full criteria for the diagnosis as long as the symptoms that are present are persistent and severe" [5, p. XXIII].
} 
the $19^{\text {th }}$ and $20^{\text {th }}$ century has today sunk into oblivion. According to Andreasen [6], the operational revolution in psychiatry and DSM's authoritative status have brought about certain unintended consequences, including a profound decline in psychopathological knowledge, which massively contributes to the current state of differentialdiagnostic disarray [7-9] and impedes both clinical work and research in psychiatry. If psychiatry is to move beyond this crisis, it seems that a rediscovery of the very bedrock of psychiatry, i.e. of psychopathology, is indeed a prerequisite. In the case of schizophrenia spectrum disorders, this rediscovery has been spearheaded by the theoretical and empirical research on self-disorders [10-12].

This research direction represents to some extent a return to and a systematic succession of a Bleulerian approach to psychopathology, i.e. focus is once more directed toward certain specific, non-psychotic features of the disorder that exhibit a trait-like quality. However, where Bleuler's fundamental symptoms generally were expressive features (i.e. signs), observable by the clinician, research on self-disorders illuminate certain subjectively lived experiential anomalies (i.e. symptoms). The purpose of this article is threefold. First, we briefly explore the concept of self, which is implied in the concept of selfdisorders, and discuss how the self may be disordered in schizophrenia spectrum disorders. Second, we present and discuss three clinical vignettes, illustrating selfdisorders and their interrelatedness in patients with schizophrenia. Finally, we offer an overview of the main empirical findings in the research on self-disorders.

\section{The self and its disorder in schizophrenia spectrum disorders}

In a famous passage from $A$ Treatise of Human Nature, Scottish philosopher David Hume described how he, through acts of introspection, sought to discover his own self:

For my part, when I enter most intimately into what I call myself, I always stumble on some particular perception or other, of heat or cold, light or shade, love or hatred, pain or pleasure. I never can catch myself at any time without a perception, and never can observe anything but the perception [13, p. 165].

Thus, Hume was unable to find his 'self' and eventually he came to question its existence-“I am certain there is no such principle in me" [13, p. 165]. Although he denied the existence of the self, this denial is in fact not at odds with the phenomenological concept of self; they are merely addressing different notions of selfhood. Where Hume searched for a substantial self (in the metaphysical sense of 'substance', i.a. an ontologically fundamental, independent thing), phenomenologists explore the self at the most basic, experiential level. According to the latter, the self cannot appear as an object in my experiential field similar to how, e.g., the book appears as an object on the table in front of me. In other words, there is no self-object in addition to the other objects in the experiential field [14]. Still, the self is not conceived as somehow absent, unconscious or as some sort of hypothetical substrate or synthesising principle below or beyond the stream of consciousness. By contrast, the proposal from phenomenology is that the self, at its most basic experiential level, manifests itself prereflectively as a certain configuration of experience [15]. More specifically, the claim is that phenomenal consciousness involves not only experiential objects but also a sense of what it is like for the subject of experience to undergo or live through her experiences. As Zahavi and Kriegel [16] put it, phenomenal consciousness entails a 'what-it-is-like-for-me-ness'. Crucially, this 'for-me-ness' of experience does not denote some kind of 'I-qualia' but articulates that experiences necessarily come with firstpersonal givenness. The phenomenological proposal is now to identity the first-personal character of experience with the 'minimal self' $[14,17]$. To exemplify, when I perceive a bottle, entertain a thought or taste an orange, I am pre-reflectively aware, i.e. without ever reflecting upon it, that I am the one who perceives a bottle, entertains a thought or tastes an orange. To put it differently, my experience of perceiving a bottle, entertaining a thought or tasting an orange come with first-personal givenness and that is precisely what makes my experiences entirely different from when I observe you perceiving, thinking, tasting, etc. The pre-reflective self-awareness, which permeates all intentional acts, crucially implies a nonobjectifying sense of self-presence. In other words, I do not need to reflect upon myself to assure myself of actually being the one who perceives, thinks or tastes, etc. Rather, we could say, with Sartre, that it is my prereflective self-awareness that renders my self-reflection possible [18, p. 9]. This is also the case in Hume's example-the 'searched-for', substantial self turned out to be an illusion, but his investigation presupposes the presence of a 'searching', experiential self for whom the illusion of the substantial self finally was revealed.

So far, we have argued that the minimal self is a necessary, built-in feature of phenomenal consciousness, i.e. a feature that no subjective experience can lack. Our claim is now that the minimal self is disordered in schizophrenia spectrum conditions $[10,19-21]$ but not in other mental disorders-a claim consistently supported by systematic, phenomenologically informed empirical studies (vide infra). In other words, in schizophrenia spectrum disor- 
ders, we are dealing with a self-disorder that is far more fundamental than any 'self-related' problems or difficult behaviours or characterological traits that may be found in disorders outside the schizophrenia spectrum, e.g., in mood, anxiety, and personality disorders. In these latter disorders, the minimal self is never at stake [22].

How, then, is the minimal self disordered in schizophrenia spectrum disorders? Recently, we have proposed a distinction between two mutually implicative aspects of the minimal self, viz. a formal aspect and an affective aspect [21]. The formal aspect depicts the first-personal givenness of experience, i.e. all experience is given to me in my first-person perspective. The affective aspect imbues the formal, first-personal structure of experience with a pre-reflective sense of self-presence or selfintimacy that persists across time and changing modalities of consciousness. It articulates an enduring, elusive, yet absolutely vital feeling of 'I-me-myself' $[10,23]$, which permeates the experiential life and provides the firstperson perspective with an inchoate sense of singularity or proto-individuation [21]. In the phenomenological tradition, this persistent sense of self-presence is perhaps best understood as an incessant, immanent auto-affection, a 'self-sensing of self' (se sentir soi-même) [24, p. 465]. The concept of self-disorders does not imply that the patient completely loses his first-person perspective or stops being a subject of experience. The instability of minimal self manifests itself in perspectival disturbances (e.g., Saks [25, p. 12f.] and Nagai [26, p. 497]), typically permeated by a diminished sense of self-presence and increasing self-alienation. The disorder of minimal self may de-structure the experiential field, affecting also its limits such as the me/not-me boundary, and facilitate an emergence of 'another presence' within the very intimacy of one's sphere of ownness [27]. This is manifest in various anomalous self-experiences such of feeling ephemeral, not truly existing or lacking an inner core. The patients often report feeling ineffably different from others (typically using the adjective "wrong" [28]), and where the sense of difference precedes any specific thematisation (such as being more stupid or less attractive than others). This phenomenon is known as 'Anderssein' [26]. The patients also describe permeable ego-boundaries (transitivism), loss of thought ipseity ('Gedankenenteignung'), audible thoughts ('Gedankenlautwerden'), thought pressure, spatialization of thoughts, various cenesthetic experiences, and 'Anwesenheit' (i.e. "an unfounded experience of the presence of another being without perceptual changes or explanatory ideas" [29, p. 143]).

Finally, a profound self-alienation may grow from within the disturbed subjectivity and, in psychosis, the sense of 'another presence' may materialize into a persecuting, influencing or hallucinatory Other [21]. In other words, many characteristic, primary psychotic experi- ences, which traditionally have been deemed bizarre or incomprehensible, can in fact be understood to some extent within this phenomenological framework [30, 31]. For example, delusions of being bugged, filmed or controlled are often merely a secondary, propositional framing of primary psychotic experiences of being 'listening to', 'watched' or 'touched' within the innermost intimacy of one's own subjectivity. A similar point can be made in the case of auditory verbal hallucinations, where the patient experiences that someone or something is 'speaking' to or about her. But who is it that is 'listening', 'watching', 'touching' or 'speaking' to or about the patient in the innermost recesses of her self? It is of course the patient herself, though she no longer is able to see it. If we are to understand these seemingly incomprehensible psychotic experiences, then we must try to understand this process in which the self becomes radically alienated from itself. In this context, self-disorders shed an illuminating light on some of the early manifestations of this process of defamiliarization.

\section{Clinical manifestations of self-disorders}

From a sample of 36 first-admitted patients, all of whom underwent a comprehensive psychopathological evaluation (for study details, see [32]), 3 patients were selected for detailed psychopathological presentation and discussion as they illustrate paradigmatic examples of self-disorders in the schizophrenia spectrum. ${ }^{3}$ The 3 patients fulfil the ICD-10 and DSM-IV diagnostic criteria for paranoid schizophrenia.

\section{Case 1}

Lisa, 26, is married but childless. She completed high school with average marks. Afterwards, she had many different jobs but she quit all because she got worse and wanted to hide it from her employees. She has by now been unemployed for 3 years. She was admitted because of suicidal ideation. She reports that her present problems began at age 12, when she experienced an inner change accompanied by anxiety and an inability to experience pleasure, causing her to seek refuge in bed for days or weeks at a time. She couldn't explain what was wrong with her, but, as she puts it, "it felt as if my brain wasn't working, as if it had shut down". Since that time, she has had outspoken concentration difficulties, with a distinct thought pressure- "my brain flickers. It is as if I have an ants' nest in my head". Disconnected thoughts and impulses break into and interfere with her main line of thoughts, making it almost impossible for her to concentrate. She also experiences that her thoughts suddenly

\footnotetext{
${ }^{3}$ Additional clinical descriptions of self-disorders in schizophrenia spectrum disorders can be found in Parnas \& Handest [33], Henriksen \& Parnas [32], Henriksen et al. [34], and Henriksen \& Nordgaard [35].
} 
"slow down, fade away, or just stop". She has always heard her thoughts as spoken aloud, internally and with her own voice, and she can locate these thoughts spatially to the back of her neck. She has concentration difficulties intertwined with attentional disturbances and a general fragmentation of meaning-"when I perceive written words, I must read them and divide them into syllables over and over again". In such situations, she feels trapped in the sense that she can't redirect her attention from the syllables to something else. This captivation of attention can also be caused by various details in her perceptual field, e.g., a nail in the wall. Moreover, she constantly doubts if an event occurred in reality, in her dreams, or in a movie, and for years she has doubted if the perceived world is truly real. Often, she experiences that others quote her saying something she can't remember having said, and this makes her wonder if it actually is her who has experienced all that or, perhaps, if everything somehow has been staged.

The patient's cognitive and concentration difficulties seem associated with more pervasive disturbances of selfawareness. Since puberty, she has not known who she is-“I don't know who I am. I'm afraid of myself, because I don't know what I might do next. I might have done something terrible I can't remember". She describes a distorted first-person perspective, i.e. she reports that it is as if she experiences herself and the world from her mouth. She describes being very anxious among others, whom she feels "can see through me and see all the bad things I have done in my life". Once, while visiting friends, her husband kindly asked her if she enjoyed cooking. She felt that he, by posing the question, "came too close", and she became anxious, paralyzed, and felt as if everybody present in the room could see through her and know her entire history. She also describes experiences of I-split, where two opposing parts of her character ceaselessly discuss even the slightest matters, making it nearly impossible for her to stay focused, initiate new lines of thoughts, and remember things for more than a few minutes.

\section{Case 2}

Ben, 27, completed high school with average marks. After two sabbatical years with changing jobs, he enrolled at the university. He completed his education and took a job abroad but was fired after a few months and returned home. He has no idea why he was fired. After a period of unemployment, he started working as a cleaning assistant but stopped because he felt that he was being watched. He felt increasingly tense and claustrophobic at work, and he became convinced that hidden cameras were filming him and he had a panic attack. Shortly after, he was hospitalized. He describes himself as a loner throughout his life, mainly with acquaintances, and he reports difficulties in socially engaging with others and a tendency to socially isolate. Already from childhood, he felt insecure, lonely, and different from others. At one point, he asked his mother if he was a robot, because, as he puts it, "I felt like I was a machine... if one could remove the face, then I thought there would be a machine inside or perhaps some other creature". He describes how everything inside his head is covered in darkness except a "light spot" at a slanted left position through and from which he perceives his thoughts and the world. He further describes the distance he experiences towards his own thoughts, "it's like watching a television from a distance of 2 meters". He perceives his thoughts as images, colours or subtitles on a movie and he reports that his head regularly "feels like a pressure boiler, spinning with thoughts". Sometimes, tough, his thoughts suddenly stop and he feels completely empty, "as if the thoughts have been shut down". He also reports multiple experiences of derealization in which the surroundings suddenly seems unreal or surreal- "as if I perceive everything through a fisheye lens" or "as if I am walking in the middle of a photography". In social situations, he often doubts if he is in fact his interlocutor, and afterwards it was, as he states, "as if I was not me". He feels considerably younger than he is, only 16 years old, and partly for this reason he often doubts if his specular image actually is reflecting him. He also describes how he feels that he is on a "time journey", where he himself remains 16, "standing still in time, with the world passing by". When walking in the street, he often senses an inexplicable link between him and objects in the environment, e.g., other people or vehicles, and he feels as if these objects have a preprogramed trajectory that eventually will make them collide with him.

\section{Case 3}

Sophia, 20, describes a changeable period in primary school, shifting school many times and eventually dropping out. She started at a production school, which she also quit. She was admitted due to suicidal ideation and self-harm. Prior to hospitalization, she felt increasingly worse, lost her will to live, and experienced a strong but inexplicable sadness regarding her existence. She describes enduring problems with common sense and an associated tendency to hyper-reflect, e.g., she often ponders questions such as why a table is called a table or why humans only have two arms instead of four or why the arms aren't placed lower to the ground, which would make it easier to pick up things. She also reports a sense of alienation towards her own body, "it is strangely assembled". The problems with common sense also manifest in the interpersonal domain, where she says, "I speculate a lot on why people do what they do? I often don't get it". She describes an excessive tendency to ruminate over 
events that happened during the day, and she finds her constant speculations oppressive and burdensome. When asked how she generally perceives the world, she replies: "it's enigmatic and strange. It's very treacherous. It really is. I am absolutely sure of it". Her perception of the world is influenced by recurrent experiences of delusional mood in which she is overwhelmed and frightened by a 'feeling that something is afoot', 'something is in the air'. Often, this feeling becomes self-referential and she feels that something foul is about to happen to her. Occasionally, this is accompanied by an apocalyptic feeling that the world is about to end. During these experiences, she regularly gets the impression that she is under surveillance and that cameras are filming her. In such situations, she may search for hidden cameras in her apartment and she is immediately calmed when she finds none. She describes her experiences of surveillance by referring to the 1998 movie The Truman Show in which the protagonist discovers that his entire life is a TV-show and that he plays the leading character surrounded by actors. Occasionally, she has the feeling as if she is the centre of the world, similar to the protagonist in the movie-"it's as if I'm in the middle surrounded by actors". In these situations, which she finds very surreal, "buildings may appear as settings and people as extras that improvise after my movements". Although she regularly can distance herself from these fleeting, but intense experiences of derealization, centrality, and self-reference, they strongly influence her life"Afterwards, you remember them and then you become suspicious. I have lost many friends and boyfriends, because I was so suspicious".

Against this backdrop of these vignettes, four observations deserve attention. First, it is worth emphasising that self-disorders, as described in the vignettes above, are not psychotic phenomena. By using phrases such as 'it feels like' or the conditional 'as if', the patients primarily indicate non-psychotic anomalies of self-experience (selfdisorders) rather than well-articulated delusions or hallucinations (e.g., "my brain flickers. It is as if I have an ants' nest in my head"). Second, the vignettes also illustrate that self-disorders are not somehow isolated, atomic-like symptoms but mutually implicative and interdependent aspects of the psychopathological Gestalt of schizophrenia. The relation between the Gestalt and its manifestations (e.g., self-disorders) is reciprocal. On the one hand, the psychopathological Gestalt confers certain typicality on its various expressive and experiential manifestations, i.e. these manifestations bear an imprint of the more global, gestaltic experiential alteration. On the other hand, the concrete manifestations also infuse the Gestalt with its specific clinical rootedness [36, 37]. Third, as indicated in the vignettes, self-disorders usually exhibit a persisting, trait-like character, i.e. they tend to articulate themselves as a nearly constant or recurring infrastructure of the patient's experiential life [28]. They are therefore unlike episodic phenomena such as a panic attack, a fleeting illusion or a temporally well-demarcated depressive episode. The altered infrastructure of consciousness manifests itself in the forms of experience (the how of experience) but also in certain typicality of experiential contents (the what of experience), e.g., being watched or expressing metaphysical concerns [38]. Fourth, patients frequently report that their self-disorders date back to childhood or early adolescence. At the time of first admission, many of the patients' self-disorders have become almost indistinctly interwoven into their very mode of experiencing, and at least partly for this reason, the patients do often not seem to experience their initial self-disorders as "symptoms" of an illness, but rather as intrinsic aspects of their existence (e.g., reflected in statements such as "it has always been like that" or "it is just who I am"). In our view, this particular aspect offers new resources for understanding the nature of poor insight into illness and treatment noncompliance in schizophrenia [27].

\section{Summary of empirical results}

The empirical research, employing the EASE scale or pre-EASE analogue scales, demonstrate the following results (for a review, see Parnas \& Henriksen [12]):

- Self-disorders hyper-aggregate in schizophrenia spectrum disorders but not in other mental disorders [39-43]

- There is no statistical difference in the level of selfdisorders among patients with schizophrenia and patients with the schizotypal disorder $[41,43]$

- Self-disorders differentiate between first-admitted cases with bipolar psychosis and schizophrenia [42] and self-disorders occur more frequently in residual schizophrenia than in remitted bipolar psychosis [44]

- Self-disorders occur in genetically high-risk individuals [45]

- Self-disorders are detectable in community samples of adolescent diagnosed as suffering from "at-risk mental state" [46] and in clinical samples of young adults at Clinical High Risk for psychosis [47]

- Prospective studies indicate that self-disorders predict transition to psychosis in an Ultra-High Risk for psychosis sample [48] and that high baseline scores of self-disorders predict later transition to a schizophrenia spectrum diagnosis $[49,50]$

- Positive correlations have been found between self-disorders and positive symptoms, negative symptoms, formal thought disorders, and perceptual disturbances, respectively [43] 
- Correlations have been found between selfdisorders and social dysfunction [51] and suicidality [52,53], respectively

- No correlations have been found between selfdisorders and IQ or neurocognitive measures [43, $54,55]$, except for impaired verbal memory [54]

- Self-disorders have been found to be temporarily stable over a 5-year period [56]

\section{Conclusion}

The concept of self-disorders has several implications. It may perhaps contribute to a more precise definition of what schizophrenia is (i.e. its 'quidditas' or 'whatness' [57]). As described by one of us [36], Bleuler struggled with the conceptualization of autism as the core of schizophrenia. The concept of autism has been abandoned in mainstream psychiatry, because of these conceptual difficulties. The view that the phenomenological essence of schizophrenia consists in a distorted self-world intentional structure, involving self-disorders and fragmentation of meaning, provides a possibility of restoring the diagnostic significance of the concept of autism. The EASE scale is one example of an empirical translation of the psychopathological insights into a clinically, applicable instrument. In the present form, the EASE scale is very time-consuming and expertise demanding, but any future shortening of this scale cannot obviate a careful semistructured, psychopathological interview. In other words, it will remain indispensable to talk to psychiatric patients and to be an experienced clinician. As a clinical phenotype, self-disorders enable the clinician with a better understanding of the patient and her problems. For the patient, it is relieving and comforting to discover that the treating psychiatrist is aware of her most intimate difficulties. Obviously, the concept of self-disorders should be explored from a psychotherapeutic perspective by designing studies in which the awareness of structural disorders of consciousness is an integral part of the therapeutic effort. In etiological research, self-disorders may serve as a basic target phenotype, thus displacing attention from current research on positive, psychotic symptoms to a research focus on the neural correlates of the basic distortions of subjectivity in schizophrenia spectrum conditions.

\section{Conflict of interest}

The authors have declared no conflict of interest.

\section{References:}

1. WHO: World Health Organization. The ICD-10 classification of mental and behavioural disorders. Clinical descriptions and diagnostic guidelines. Geneva; WHO: 1992.

2. APA: American Psychiatric Association. Diagnostic and Statistical Manual of Mental Disorders: DSM-5. Arlington; APA: 2013.
3. Bleuler E. Dementia Praecox or the Group of Schizophrenias, trans. by J. Zinkin. New York; International Universities: 1950.

4. Parnas J., Bovet P., Zahavi D. Schizophrenic autism: clinical phenomenology and pathogenetic implications. World Psychiatry, 2002; 1(3): 131-136.

5. APA: American Psychiatric Association. Diagnostic and Statistical Manual of Mental Disorders: DSM-IV. Washington, DC; APA: 1994.

6. Andreasen N. DSM and the death of phenomenology in America: an example of unintended consequences. Schizophr Bull, 2007; 33: 108-112.

7. Parnas J., Bovet P. Psychiatry made easy: operation(al)ism and some of its consequences. In: Kendler K., Parnas J. (eds), Philosophical issues in psychiatry III: the nature and sources of historical science. Oxford; Oxford University Press: 2015, pp. 190-212.

8. Parnas J. Differential diagnosis and current polythetic classification. World Psychiatry, 2015; 14: 284-287.

9. Parnas J. Diagnostic epidemics and diagnostic disarray: the issue of differential diagnosis. In: Kendler K., Parnas J (eds), Philosophical Issues in Psychiatry IV. Oxford; Oxford University Press: 2017, 143-145.

10. Sass L.A., Parnas J.: Schizophrenia, consciousness, and the self. Schizophr Bull, 2003; 29: 427-444.

11. Parnas J., Møller P., Kircher T., Thalbitzer J., Jansson L., Handest P., et al. EASE: Examination of anomalous self-experience. Psychopathology, 2005; 38: 236-258.

12. Parnas J., Henriksen M.G. Disordered self in the schizophrenia spectrum: A clinical and research perspective. Harv Rev Psychiatry, 2014; 22: 251-265.

13. Hume D. A Treatise of Human Nature. New York; Oxford University Press: 2007.

14. Zahavi D. Thin, Thinner, Thinnest: Defining the Minimal Self. In Durt C., Fuchs T., Tewes C. (eds.), Embodiment, Enaction, and Culture. Investigating the Constitution of the Shared World. Cambridge, MA.; The MIT Press: 2017, pp. 193-199.

15. Zahavi D. Subjectivity and Selfhood. Investigating the FirstPerson Perspective. Cambridge, MA; MIT Press: 2005.

16. Zahavi D., Kriegel U. For-Me-Ness: What It Is and What It Is Not. In Dahlstrom D.O., Elpidorou A., Hopp W. (eds), Philosophy of Mind and Phenomenology: Conceptual and Empirical Approaches. New York; Routledge: 2016, pp. 36-53.

17. Zahavi D. Self and Other: Exploring Subjectivity, Empathy, and Shame. Oxford; Oxford University Press: 2014.

18. Sartre J.P. Being and Nothingness, trans. H. E. Barnes. London; Routledge: 2003.

19. Cermolacce M., Naudin J., Parnas J. The 'minimal self' in psychopathology: Re-examining the self-disorders in the schizophrenia spectrum. Conscious Cogn, 2007; 16: 703-714.

20. Nelson B., Parnas J., Sass L.A. Disturbance of minimal self (ipseity) in schizophrenia: Clarification and current status. Schizophr Bull, 2014; 40: 479-482.

21. Parnas J., Henriksen M.G. Schizophrenia and mysticism: A phenomenological exploration of the structure of consciousness in the schizophrenia spectrum disorders. Conscious Cogn, 2016; 43: 75-88.

22. Parnas J., Henriksen, M.G. Selfhood and its disorders. In: Stanghellini G., Broome M., Fusar-Poli P., Fernandez A., Rosfort R., Raballo A. (eds), The Oxford Handbook of Phenomenological Psychopathology. Oxford; Oxford University Press: in press.

23. Hart J.G. Who One Is. Book 1. Meontology of the 'I': A Transcendental Phenomenology. Berlin; Springer: 2009.

24. Henry M. The essence of manifestation, trans. Etzkorn G. The Hague; Martinus Nijhoff: 1973.

25. Saks E.R. The center cannot hold. New York; Hyperion: 2007.

26. Nagai M. The "schizophrenic" in the self-consciousness of schizophrenic patients. Hist Psychiatry, 2016; 27: 493-503. 
27. Henriksen M.G., Parnas J. Self-disorders and schizophrenia: A phenomenological reappraisal of poor insight and noncompliance. Schizophr Bull, 2014; 40: 542-547.

28. Parnas J., Henriksen M.G. Disturbance of the experience of self - a phenomenologically based approach. In Waters F., Stephane M. (eds), The assessment of psychosis: a reference book and rating scales for research and practice. New York; Routledge: 2015, pp. 235-244.

29. Jansson L., Nordgaard J. The psychiatric interview for differential diagnosis. Switzerland; Springer: 2016.

30. Henriksen M.G. On incomprehensibility in schizophrenia. Phenom Cogn Sci, 2013; 12: 105-129.

31. Parnas J., Henriksen M.G. Subjectivity and schizophrenia: another look at incomprehensibility and treatment non-adherence. Psychopathology, 2013; 46 (5): 320-329.

32. Henriksen M.G., Parnas J. Clinical manifestations of self-disorders and the Gestalt of schizophrenia. Schizophr Bull, 2012; 38: 657-660.

33. Parnas J., Handest P. Phenomenology of Anomalous Experiences in Early Schizophrenia. Compr Psychiatry, 2003; 44: 121-134.

34. Henriksen M.G., Raballo A., Parnas J. The pathogenesis of auditory verbal hallucinations in schizophrenia: a clinical-phenomenological account. Philos Psychiatr Psychol, 2015; 22: 165-181.

35. Henriksen M.G., Nordgaard J. Self-disorders in Schizophrenia. In Stanghellini G., Aragona M. (eds), An Experiential Approach to Psychopathology. What is it like to suffer from mental disorders. New York; Springer: 2016, pp. 265-280.

36. Parnas J. A disappearing heritage: the clinical core of schizophrenia. Schizophr Bull, 2011; 37: 1121-30.

37. Parnas J. The core Gestalt of schizophrenia. World Psychiatry, 2012; 11(2): 67-69.

38. Bovet P., Parnas J. Schizophrenic delusions: a phenomenological approach. Schizophr Bull, 1993; 19: 579-597.

39. Parnas J., Handest P., Jansson L., Sæbye D. Anomalous subjective experience among first-admitted schizophrenia spectrum patients: empirical investigation. Psychopathology, 2005b; 38: 259-267.

40. Raballo A., Sæbye D., Parnas J. Looking at the schizophrenia spectrum through the prism of self-disorders: an empirical study. Schizophr Bull, 2011; 37: 344-351.

41. Raballo A., Parnas J. Examination of anomalous self-experience: Initial study of the structure of self-disorders in schizophrenia spectrum. J Nerv Ment Dis, 2012; 200: 577-583.

42. Haug E., Lien L., Raballo A. Bratlien U., Øie M., Andreassen O.A., et al. Selective aggregation of self-disorders in first-treatment DSM-IV schizophrenia spectrum disorders. J Nerv Ment Dis, 2012; 200: 632-636.

43. Nordgaard J., Parnas J. Self-disorders and schizophreniaspectrum: A study of 100 first hospital admissions. Schizophr Bull, 2014; 40: 1300-1307.

44. Parnas J., Handest P., Sæbye D., Jansson L. Anomalies of subjective experience in schizophrenia and psychotic bipolar illness. Acta Psychiatr Scand, 2003; 108: 126-133.

45. Raballo A., Parnas J. The silent side of the spectrum: schizotypy and the schizotaxic self. Schizophr Bull, 2011; 37: 1017-1026.

46. Koren D., Reznik N., Adres M., Scheyer R., Apter A., Steinberg T., et al. Disturbances of basic self and prodromal symptoms among nonpsychotic help-seeking adolescents. Psychol Med, 2013; 43: 1365-76.

47. Raballo A., Pappagallo E., Dell' Erba A., Lo Cascio N., Patane' M., Gebhardt E., et al. Self-disorders and clinical high risk for psychosis: an empirical study in help-seeking youth attending Community mental health facilities. Schizophr Bull, 2016; 42: 926-32.

48. Nelson B., Thompson A., Yung A.R. Basic self-disturbance predicts psychosis onset in the ultra high risk for psychosis 'prodromal' population. Schizophr Bull, 2012; 38: 1277-1287.

49. Parnas J., Raballo A., Handest P., Jansson L., Vollmer-Larsen A., Sæbye D. Self-experience in the early phases of schizophrenia: 5- year follow-up of the Copenhagen Prodromal Study. World Psychiatry, 2011; 10: 200-204.

50. Parnas J., Carter J., Nordgaard J. Premorbid self-disorders and lifetime diagnosis in the schizophrenia spectrum: a prospective high-risk study. Early Interv Psychiatry, 2016; 10: 45-53.

51. Haug E., Øie M., Andreassen O.A., Bratlien U., Raballo A., Nelson B., et al. Anomalous self-experiences contribute independently to social dysfunction in the early phases of schizophrenia and psychotic bipolar disorder. Compr Psychiatry, 2014; 55: 475-82.

52. Skodlar B., Parnas J. Self-disorder and subjective dimensions of suicidality in schizophrenia. Compr Psychiatry, 2010; 51: 363-6.

53. Haug E., Melle I., Andreassen O.A., Raballo A., Bratlien U., Øie M. et al. The association between anomalous self-experience and suicidality in first-episode schizophrenia seems mediated by depression. Compr Psychiatry, 2012; 53: 456-60.

54. Haug E., Øie M., Melle I., Andreassen O.A., Raballo A., Bratlien U., et al. The association between self-disorders and neurocognitive dysfunction in schizophrenia. Schizophr Res, 2012; 135: 79-83.

55. Nordgaard J., Revsbech R., Henriksen M.G. Self-disorders, neurocognition, and rationality in schizophrenia: A preliminary study. Psychopathology, 2015; 48: 310-316.

56. Nordgaard J., Handest P., Vollmer-Larsen A., Sæbye D., Thejlade Pedersen J., Parnas J. Temporal persistence of anomalous selfexperience: A 5 years follow-up. Schizophr Res, 2017; 179: 36-40.

57. Maj M. The critique of DSM-IV operational criteria for schizophrenia. Brit J Psychiatry, 1998; 172: 458-460.

\section{Correspondence address}

Dr. Mads Gram Henriksen,

Mental Health Center Glostrup,

Broendbyoestervej 160,

DK-2605 Broendby, Denmark.

Email: mgh@hum.ku.dk

Received: 31.05.2017

Revised: 07.06.2017, 12.06.2017

Accepted: 03.07.2017

Published: 30.08 .2017 